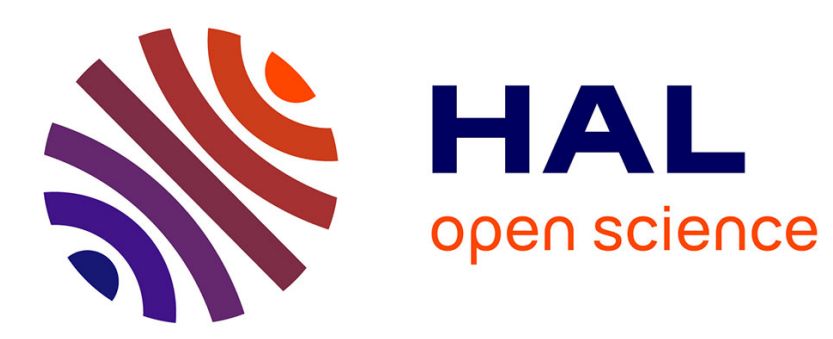

\title{
Power Management of a Smart Vehicle-to-Grid (V2G) System Using Fuzzy Logic Approach
}

Majid Mehrasa, Reza Razi, Khaled Hajar, Antoine Labonne, Ahmad Hably, Seddik Bacha

\section{- To cite this version:}

Majid Mehrasa, Reza Razi, Khaled Hajar, Antoine Labonne, Ahmad Hably, et al.. Power Management of a Smart Vehicle-to-Grid (V2G) System Using Fuzzy Logic Approach. IECON 2021 - The 47th Annual Conference of the IEEE Industrial Electronics Society, Oct 2021, Toronto (virtual ), Canada. 10.1109/IECON48115.2021.9589039 . hal-03410205

\section{HAL Id: hal-03410205 \\ https://hal.science/hal-03410205}

Submitted on 31 Oct 2021

HAL is a multi-disciplinary open access archive for the deposit and dissemination of scientific research documents, whether they are published or not. The documents may come from teaching and research institutions in France or abroad, or from public or private research centers.
L'archive ouverte pluridisciplinaire HAL, est destinée au dépôt et à la diffusion de documents scientifiques de niveau recherche, publiés ou non, émanant des établissements d'enseignement et de recherche français ou étrangers, des laboratoires publics ou privés. 


\section{Power Management of a Smart Vehicle-to-Grid (V2G) System Using Fuzzy Logic Approach}

\author{
Majid Mehrasa \\ Univ. Grenoble Alpes, CNRS, \\ Grenoble INP, G2ELAB, 38000 \\ Grenoble, France \\ majid.mehrasa@g2elab.grenoble- \\ inp.fr
}

\author{
Reza Razi \\ Univ. Grenoble Alpes, CNRS, \\ Grenoble INP, GIPSA-Lab, \\ 38000 Grenoble, France \\ reza.razi@grenoble-inp.fr
}

Ahmad Hably

Univ. Grenoble Alpes, CNRS, Grenoble INP, GIPSA-Lab, 38000 Grenoble, France ahmad.hably@gipsalab.grenoble-inp.fr

\begin{abstract}
Smart charging/discharging of Plug-in Electric Vehicles (PEVs) is definitely able to bring a significant cost benefit for both EV station owners and EV owners as well. To this end, this paper develops a Mamdani-based fuzzy strategy with the inputs including the forecasted and real PV generation data, electricity price, and the instantaneous state-of-charging (SOC). Moreover, the output power of PEVs is considered as the output of the proposed strategy. In order to attain further smooth and accurate power sharing for PEVs, varied output rules are assigned commensurate with the rated power of each PEVs. In addition, another fuzzy strategy is developed using the instantaneous SOC error to establish a specified SOC for PEVs at the departure time. While two PV panel profiles are taken into account, Simulation in MATLAB/Simulink environment presents accurate and acceptable results from SOCs of PEVs, PEVs output power, prices and grid power.
\end{abstract}

Keywords - Smart Charging, Plug-in Electric Vehicles (PEVs), Fuzzy Logic Control, State-of-Charging (SOC).

\section{INTRODUCTION}

The numbers of electric vehicles (EVs) have been estimated to globally surpass 35 million [1] and 100 million [2] by 2022 and 2028, respectively. It provides this opportunity for researchers and industrial companies to deeply deal with smart charging of EVs especially based on the cost-benefit criteria in both Vehicle-to-Grid (V2G) and Grid-to-Vehicle (G2V) applications [3-4]. Among different optimal strategies for Electric Vehicles (EVs) [5], researches worked on techniques such as Escort Evolutionary Game [6], Reinforcement Learning Technique [7], Mixed Strategy [8], Linear Quadratic Gaussian [9], and Linear Programing [10].

But, in order to adopt smart charging/discharging algorithms for much more effective control of EVs, two rulebased control strategies have been proposed including Deterministic Rule-Based Methods (DRMs) and Fuzzy-Rule-

This work has been supported by the aVEnir project of the PIA operated by ADEME.

\author{
Khaled Hajar \\ Univ. Grenoble Alpes, CNRS, \\ Grenoble INP, GIPSA-Lab, \\ 38000 Grenoble, France \\ khaled.hajar@grenoble-inp.fr
}

\author{
Antoine Labonne \\ Univ. Grenoble Alpes, CNRS, \\ Grenoble INP, G2ELAB, 38000 \\ Grenoble, France \\ antoine.labonne@g2elab.grenobl \\ e-inp.fr
}

Seddik Bacha Univ. Grenoble Alpes, CNRS, Grenoble INP, G2ELAB, 38000 Grenoble, France seddik.bacha@g2elab.grenobleinp.fr

Based Controllers (FRCs) [11]. In DRMs, the rules are ascertained prior to the actual operation of the system under control. In contrast, FRCs are featured by robustness against uncertainty and easy adjustment as well [12]. In addition, FRCs have fast performance with significant computational burden mitigation and the excellent secession capability of multiple controllers [13]. As a consequence, as one of the most effective strategies for smart charging of EVs, it is highly worthy to investigate various kinds of FRCs in the frame of different industrial applications.

FRCs-based smart charging strategies focused on various industrial challenges [14]-[15]. For instance, a fuzzy control technique was proposed by [16] to assign power coordination between EVs and power grid against Point of Common Coupling (PCC) voltage fluctuations. In this technique, the final charging/discharging rate and SOC of EVs battery were taken into account. Also, in [17], a fully decentralized controller was designed based on fuzzy logic technique with the input parameters driven from the power grid, EV charger and EV battery pack. This technique was aimed to reach a suitable EV charger for regulating the charging current against power grid instability. On the other hand, an adaptive fuzzy was established to accurately execute the $\mathrm{EV}$ prioritization process for simultaneously attaining the storage utilization maximization and the charging cost minimization [18]. In order to highly achieve precise charging/discharging points for connected EVs in presence of uncertainties coming from the electric grid and EVs, a fuzzy logic control was proposed in [19] to manage the efficient power available in the EVs of the parking lot. A fuzzy strategy was incorporated by grid constraints to specify the score of each PEV in the charging process aiming to maximize the owner's satisfaction based on the delivered energy [20]. The FRCs were also employed in energy management of hybrid electric autonomous vehicle [21], the intelligent control of a 
vehicle-to-grid system [22], and Big Data Analysis Technology of PEVs [23].

In this paper, a fuzzy-based smart charging technique is proposed for the smart grid shown in Fig. 1 to attain an accurate charging and discharging states for PEVs. Since V2G discharging challenges [24] and minimum peak load [25] are two very important targets, in the proposed technique, the PEVs are intended for attaining the cost benefit when both V2G and load consumption are instantaneously taken into account. Hereby, it is aimed to increase the power injection from PEVs to power grid while the price is increasing as well. As another target, each PEV should have a specified SOC at the departure time. Consequently, a new fuzzy strategy is developed through the instantaneous SOC error with the specified SOC as the reference set-point. This paper organizes as the follows. Section I focuses on the literature review. Proposed Fuzzy-based smart charging strategy is developed in Section II. This section consists of two sub-sections including the charging/discharging control of PEVs and SOC setting at the departure time. These sub-sections also investigate the effects of PV power, price and SOC error on the PEVs output power. The simulation results including SOCs of PEVs, PEVs output power, prices and grid power are discussed in Section III. Conclusion is presented in Section IV.

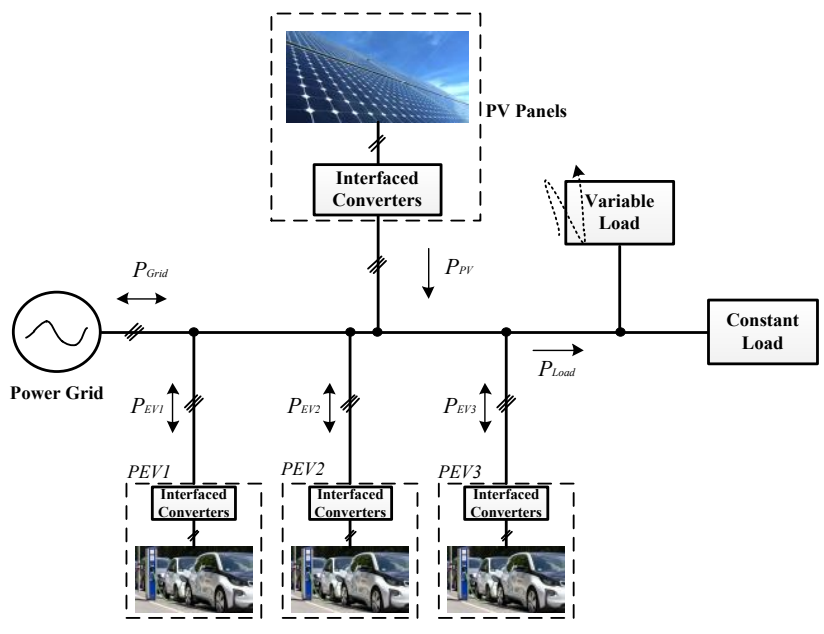

Fig. 1. The smart grid under study.

\section{Proposed Fuzzy-Based Smart Charging Strategy}

In this paper, the smart grid shown in Fig. 1 is taken into account. Based on this figure, the smart grid consists of three PEV, power grid, PV panels and load including both constant and variable loads. The power grid and PEVs are able to provide bidirectional power flow. The PV panels inject an unidirectional power to PCC with the profiles shown in Fig. 2(a). The total load has a profile according to Fig. 2(b).

\section{A. The Charging/Discharging Control of PEVS}

In order to reach the cost benefits, the PEVs in the considered smart grid should be managed through paying attention to minimum and maximum prices. On the other hand, knowing the variation trend of the PV power can facilitate reaching more cost benefit and utilization of PV panel power. Also, when SOC is monitored, it helps highly PEVs make a decision to stay at charging or discharging state. Based on the smart grid in Fig. 1, the proposed smart charging/discharging strategy is aimed to achieve the following targets,

- The PV panels power must be utilized for charging the PEVs as much as possible.

- The power injection amount from PEVs to grid must be increased while the price is increasing as well.

- The charging process of PEVs must be prioritized by PV panels. But, the power injection amount from grid to PEVs must be increased while the price is decreasing.

Using the aforementioned targets and noticing the price profile depicted in Fig. 2(c), the proposed fuzzy strategy is devised based on the Table I.

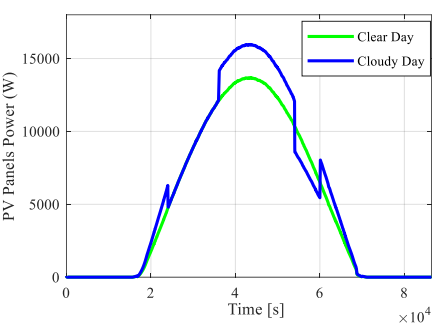

(a)

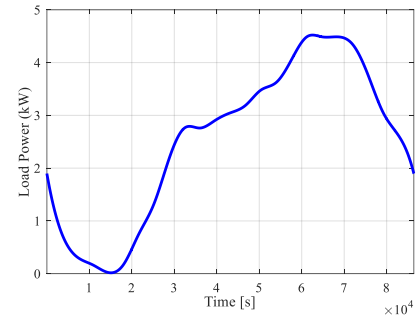

(b)

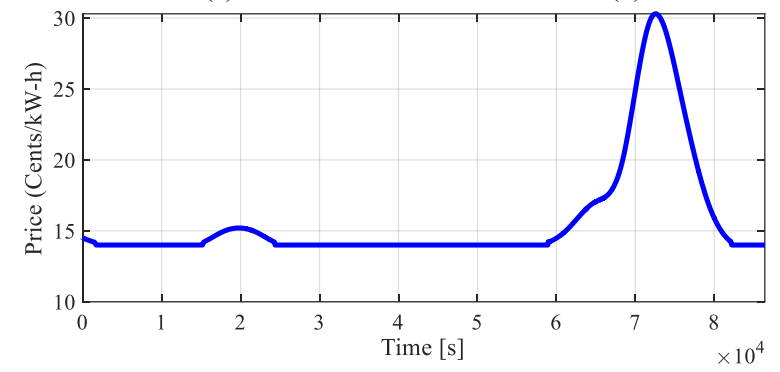

(c)

Fig. 2. (a) PV panel power profiles in two states of clear day and cloudy day, (b) Load power profile, and (c) the price profile.

As it can be seen from this table, the states of Low (L), Medium (M) and High $(\mathrm{H})$ are defined for all SOCs of PEVs, the PV panels power and the price. For the charging (C) and discharging (DC) modes in the output of fuzzy strategy, Very High $(\mathrm{VH})$ and Zero $(\mathrm{Z})$ are taken into consideration as well. The weight factor for each rule is set on " 1 " in this paper. The Mamdani Fuzzy Inference System (FIS) type with the Trapezoidal membership function are employed. A typical Trapezoidal membership function is illustrated in Fig. 3.

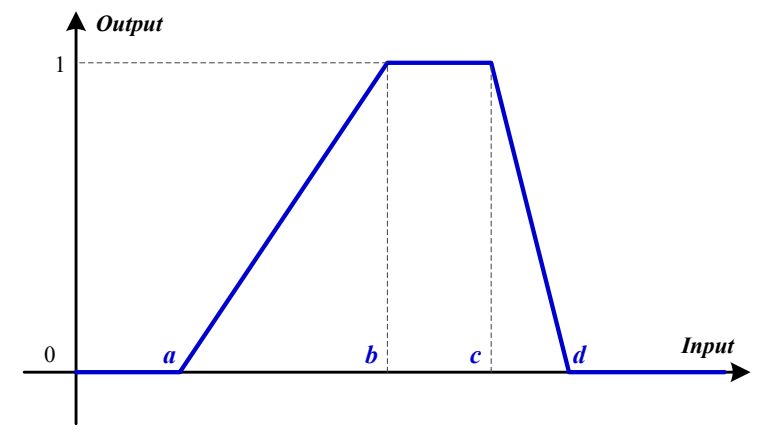

Fig. 3. Trapezoidal membership function for proposed Fuzzy strategy. 
Table I. The rules of proposed fuzzy charging/discharging strategy for PEVs.

\begin{tabular}{|c|c|c|c|c|c|c|c|c|c|c|c|c|c|c|c|}
\hline & \multicolumn{3}{|c|}{ Inputs } & \multicolumn{3}{|c|}{ Outputs } & & & \multicolumn{3}{|c|}{ Inputs } & \multicolumn{3}{|c|}{ Outputs } & \multirow[b]{2}{*}{$\begin{array}{l}\text { Weight } \\
\text { of Rule }\end{array}$} \\
\hline No & SOC & Ppv & Price & PEV1 & PEV2 & PEV3 & $\begin{array}{l}\text { Weight } \\
\text { of Rule }\end{array}$ & No & SOC & Ppv & Price & PEV1 & PEV2 & PEV3 & \\
\hline 1 & $L S$ & $L p v$ & $L P$ & $\mathrm{MC}$ & VHC & $\mathrm{HC}$ & 1 & 15 & $M S$ & $M p v$ & $H P$ & VHDC & VHDC & VHDC & 1 \\
\hline 2 & $L S$ & $L p v$ & $M P$ & LC & MC & LC & 1 & 16 & $M S$ & $H p v$ & $L P$ & LC & $\mathrm{HC}$ & $\mathrm{MC}$ & 1 \\
\hline 3 & $L S$ & $L p v$ & $H P$ & Z & Z & $\mathrm{Z}$ & 1 & 17 & $M S$ & $H p v$ & $M P$ & LC & $\mathrm{MC}$ & LC & 1 \\
\hline 4 & $L S$ & $M p v$ & $L P$ & $\mathrm{MC}$ & VHC & $\mathrm{HC}$ & 1 & 18 & $M S$ & $H p v$ & $H P$ & VHDC & VHDC & VHDC & 1 \\
\hline 5 & $L S$ & $M p v$ & $M P$ & $\mathrm{MC}$ & VHC & $\mathrm{HC}$ & 1 & 19 & $H S$ & $L p v$ & $L P$ & $\mathrm{Z}$ & Z & $\mathrm{Z}$ & 1 \\
\hline 6 & $L S$ & $M p v$ & $H P$ & LC & $\mathrm{MC}$ & LC & 1 & 20 & $H S$ & $L p v$ & $M P$ & VHDC & VHDC & VHDC & 1 \\
\hline 7 & $L S$ & $H p v$ & $L P$ & $\mathrm{MC}$ & VHC & $\mathrm{HC}$ & 1 & 21 & $H S$ & $L p v$ & $H P$ & VHDC & VHDC & VHDC & 1 \\
\hline 8 & $L S$ & $H p v$ & $M P$ & $\mathrm{MC}$ & VHC & $\mathrm{HC}$ & 1 & 22 & $H S$ & $M p v$ & $L P$ & LC & $\mathrm{MC}$ & LC & 1 \\
\hline 9 & $L S$ & $H p v$ & $H P$ & $\mathrm{LC}$ & $\mathrm{HC}$ & $\mathrm{MC}$ & 1 & 23 & $H S$ & $M p v$ & $M P$ & LC & $\mathrm{MC}$ & LC & 1 \\
\hline 10 & $M S$ & $L p v$ & $L P$ & $\mathrm{MC}$ & VHC & $\mathrm{HC}$ & 1 & 24 & $H S$ & $M p v$ & $H P$ & VHDC & VHDC & VHDC & 1 \\
\hline 11 & $M S$ & $L p v$ & $M P$ & VHDC & VHDC & VHDC & 1 & 25 & $H S$ & $H p v$ & $L P$ & LC & $\mathrm{MC}$ & LC & 1 \\
\hline 12 & $M S$ & $L p v$ & $H P$ & VHDC & VHDC & VHDC & 1 & 26 & $H S$ & $H p v$ & $M P$ & LC & $\mathrm{HC}$ & $\mathrm{MC}$ & 1 \\
\hline 13 & $M S$ & $M p v$ & $L P$ & $\mathrm{LC}$ & $\mathrm{MC}$ & $\mathrm{LC}$ & 1 & 27 & $H S$ & $H p v$ & $H P$ & VHDC & VHDC & VHDC & 1 \\
\hline 14 & $M S$ & $M p v$ & $M P$ & $\mathrm{LC}$ & $\mathrm{MC}$ & $\mathrm{LC}$ & 1 & & & & & & & & \\
\hline
\end{tabular}

Based on Fig. 3, the output of proposed Fuzzy strategy is obtained through (1),

$$
f(x ; a, b, c, d)=\left\{\begin{array}{cl}
0, & x \leq a \\
\frac{x-a}{b-a}, & a \leq x \leq b \\
1, & b \leq x \leq c \\
\frac{d-x}{d-c}, & c \leq x \leq d \\
0, & x \geq d
\end{array}\right.
$$

Where $x$ and $f($.) are the input and output of the fuzzy system, respectively. The parameters $a, b, c$ and $d$ are chosen by the designer and they can highly impact on the final value of the fuzzy system output. The relation (1) can be also stated as the following by using the S-norm function,

$$
f(x ; a, b, c, d)=\max \left(\min \left(\frac{x-a}{b-a}, 1, \frac{d-x}{d-c}\right), 0\right)
$$

According to Table III, the PEVs with different rated output power are exerted. It can be concluded that the charging and discharging rate differs for each PEVs. This point is employed to determine the Fuzzy rules for PEVs output power based on Table I. As it can be realized from this table, the charging and discharging rate is boosted in order as PEV1, PEV3, and PEV2. Also, in the proposed Fuzzy-based smart charging, the utilization of PV panel power takes priority over cost benefit when the SOC is in low level. This priority is seen in the rules 5, 6, 8 and 9, as given in Table I. In addition, excepted for the rules 6 and 9, all PEVs start discharging with very high rate when the price is high as determined in the rules $12,15,18,21,24$, and 27 . Using the Table I, a fuzzy rule-based $3 \mathrm{D}$ curve is achieved for each PEV based on the price and the PV panel power as it is depicted in Fig. 4.

In this figure, it can be understood when the price is increasing, all PEVs tend to be discharged more. It should be also noticed that the maximum discharging happens for PEVs when the PV panel power is approximately zero and the price is equal to its maximum value. On the other hand, as it can be figured out from Fig. 4(a), (b) and (c), in the midpoints of the price and PV panels power, all PEVs reach the maximum charging from the proposed strategy point of view. In order to compare the Fuzzy rules performance for three PEVs, the PEV output power is plotted based on PV panel power and price in Fig. 5(a) and (b), respectively.

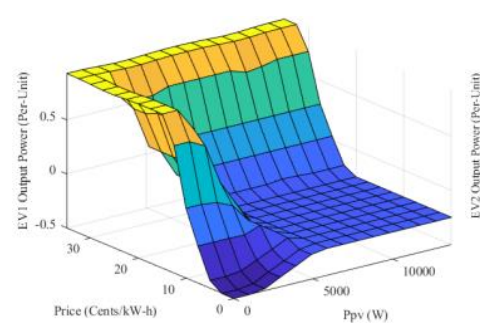

(a)

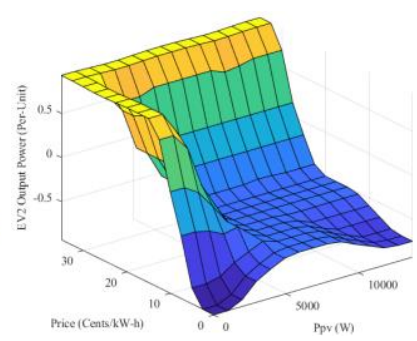

(b)

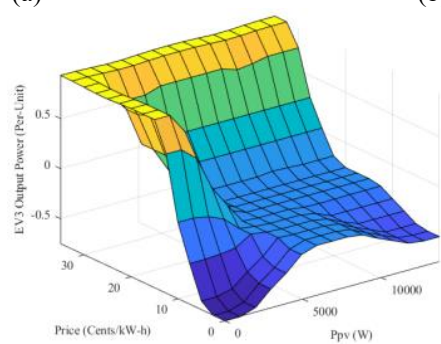

(c)

Fig. 4. The fuzzy rule-based 3D curves based on the price and the PV panel power for (a) PEV1, (b) PEV2, and (c) PEV3.

In both figures, it is obvious that the same results are achieved for the PEV1 and PEV2. Fig. 5(a) illustrates that there is the same trend for the output power of PEVs in which all PEVs are able to attain the maximum charging point after around $P_{p v}=6 \mathrm{~kW}$. According to this figure, the PEV1 and PEV3 keep their discharging state in the interval $[0 \mathrm{~kW} 4 \mathrm{~kW}]$ which is more than the PEV2 within interval [0kW $3.7 \mathrm{~kW}]$. Within the mentioned intervals, the discharging rate of PEVs is continuously mitigated with a constant ramp as depicted in Fig. 5(a). It can be observed from Fig. 5(b) when the price is within the interval [0 Cents $/ \mathrm{kW}-\mathrm{h} 20$ Cents $/ \mathrm{kW}$-h], the output power of all PEVs is maximally charged. However, the PEV1 and PEV3 have less charging degree (-0.23 Per-Unit) in comparison with the PEV2 (-0.5 Per-Unit). It means that the PEV1 and 
PEV3 save more money while the power grid is the responsible of charging the PEVs and the price is medium. Inversely, when the price is low and the power grid is the responsible of charging PEVs, the PEV2 can bring more cost benefit for both PEVs station owner and PEVs owner. But, after the price 20 Cents $/ \mathrm{kW}-\mathrm{h}$, the discharging degree of all PEVs is increased with constant rate as depicted in Fig. 5(b). There is slight difference between the discharging trend of all PEVs, although the PEV1 and PEV3 have higher the discharging degree compared to the PEV2. It is worth mentioning when the price is going ahead its maximum value, all PEVs completely provide maximum power injection to the power grid as achieved in Fig. 5(b).

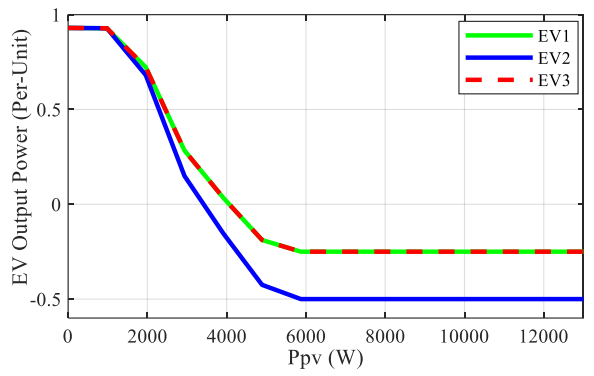

(a)

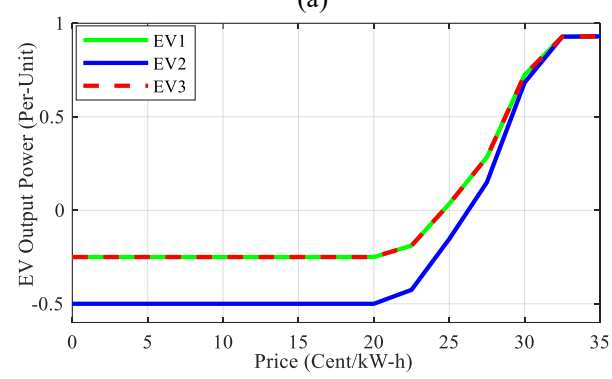

(b)

Fig. 5. Comparison between the Fuzzy rules of three PEVs output power based on (a) PV panel power, and (b) Price.

\section{B. SOC Setting at the Departure Time}

Another important target of the proposed smart charging/discharging strategy is to enforce the PEVs to have a specified SOC at the departure time from charging station. For SOC setting at the departure time, a new set of rules based on the instantaneous error of SOC is schemed as presented in Table II. The instantaneous SOC error is defined as the following,

$e_{S O C}^{i}=S O C_{\text {Final }}^{i}-S O C^{i}$

The proposed strategy in this sub-section utilizes the Mamdani FIS type with the Trapezoidal membership function as well. Thus, the output of the fuzzy strategy is achieved through,

$$
\begin{aligned}
& P E V^{i}\left(e_{S O C}^{i}, a^{i}, b^{i}, c^{i}, d^{i}\right)= \\
& \max \left(\min \left(\frac{e_{S O C}^{i}-a^{i}}{b^{i}-a^{i}}, 1, \frac{d^{i}-e_{S O C}^{i}}{d^{i}-c^{i}}\right), 0\right)
\end{aligned}
$$

Where " $i$ " stands for the $i^{\text {th }} \operatorname{PEV~(i=1,2,3).~In~Table~II,~the~}$ abbreviations of the symbols mean B (Big), M (Medium), L (Low), P (Positive) and N (Negative). As it can be seen from
Table II, the same rules are developed for PEV2 and PEV3, and different rules with less charging and discharging rate are made for PEV1 because of its higher-rated power. In order to compare the effects of the fuzzy rules on the charging/discharging degrees of the PEVs output power, Fig. 6 is plotted by using the rules in Table II. In Fig. 6, the inequalities of $e^{i}{ }_{S O C}>0$ and $e^{i}{ }_{S O C}<0$ mean that the PEV must be within the charging and discharging modes, respectively. To assess Fig. 6, as it is predicted, when the positive values of $e^{i}{ }_{S O C}$ is increased, the PEVs charging degree of proposed strategy must be increased as well. Moreover, inversely, while the negative values of $e^{i}{ }_{S O C}$ is decreasing, the PEVs output power should start discharging with constant rate.

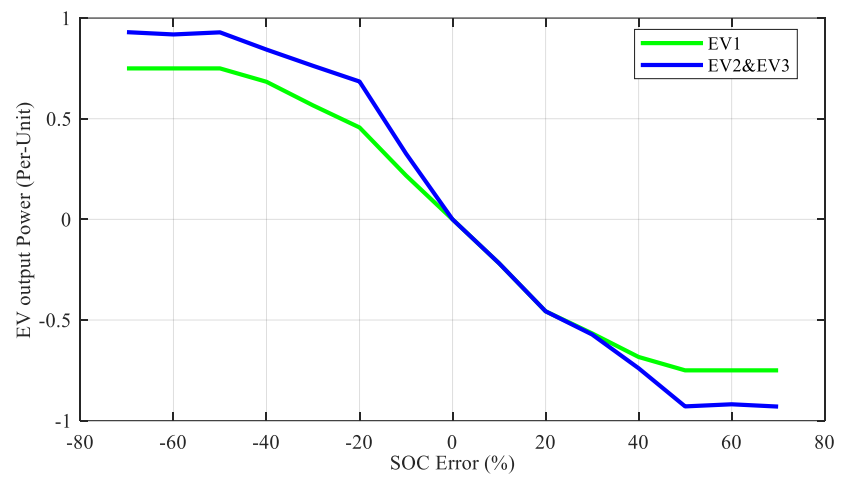

Fig. 6. Comparison between the charging/discharging degrees of the PEVs output power.

Table II. The rules for SOC setting at the departure time

\begin{tabular}{|l|c|c|c|c|c|c|c|}
\hline no & 1 & 2 & 3 & 4 & 5 & 6 & 7 \\
\hline$e_{\text {SOC }}^{i}$ & BP & MP & LP & Z & LN & MN & BN \\
\hline PEV1 & HC & HC & MC & Z & MDC & HDC & HDC \\
\hline PEV2 & VHC & VHC & MC & Z & HDC & VHDC & VHDC \\
\hline PEV3 & VHC & VHC & MC & Z & HDC & VHDC & VHDC \\
\hline
\end{tabular}

TABLE III: THE PARAMETERS FOR SimUlATION TEST

\begin{tabular}{cc}
\hline \hline Definition & Value \\
Rated maximum/minimum power of PEV1 & $22 /-22 \mathrm{kV}$ \\
Rated maximum/minimum power of PEV2 & $7.4 /-7.4 \mathrm{kV}$ \\
Rated maximum/minimum power of PEV3 & $11 /-11 \mathrm{kV}$ \\
Maximum/minimum PEVs SOC & $90 \%, 20 \%$ \\
Final SOC for PEV1, PEV2 and PEV2 & $70 \%, 80 \%, 60 \%$ \\
\hline \hline
\end{tabular}

\section{Simulation Results}

The proposed smart charging/discharging strategy is evaluated through MATLAB/Simulink enviorment while two PV panels profiles are taken into account according to Fig. 2(a). The simulation parameters are demonstrated in Table III. As it can be seen from this table, the final SOC of three PEVs at departure time should be $70 \%, 80 \%$ and $60 \%$, respectively. The end of the simulation is considered as the departure time for all PEVs. According to Table III, the PEV2 has less rated power leading to bigger charging degree in the proposed Fuzzy rules comapred to other PEVs as exhibited in Fig. 5. In addition, 
the SOC in the rules of proposed fuzzy charging/discharging strategy is chosen between $20 \%$ and $90 \%$. This section includes two sub-sections focusing on power analysis as well as the SOC and price analysis.

\section{A. The Power Analysis}

Fig. 7 shows the output power of three PEVs for clear and cloudy days. According to Fig. 7, using the proposed strategy, the PEV2 is set to be charged through PV panels much more than the PEV1 and PEV3 in both clear and cloudy days. After the PEV2 is fully charged, the PEV1 and PEV3 still remain at charging mode as depicted in Fig. 7(a) and (b). By noticing Fig. 2(c), the proposed smart charging/discharging strategy can be evaluated at the peak price. When the price is within its peak period, the proposed strategy is able to enforce the discharging mode with very high rate for all PEVs as can be observed from Fig. 7(a) and (b). Based on these figures, the PEV2, PEV3, and PEV1 contribute respectively to transforming power from PEVs to the grid.

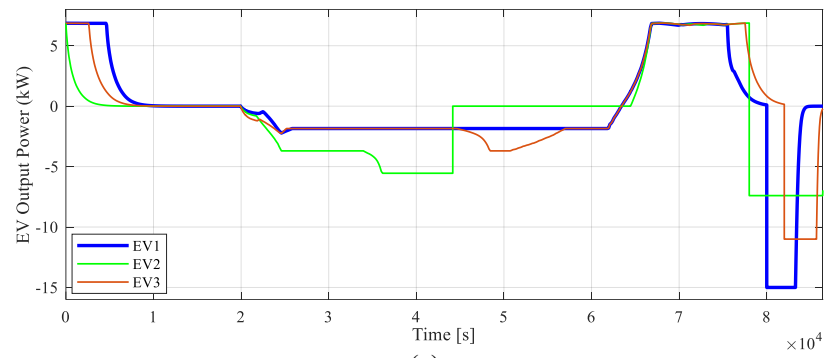

(a)

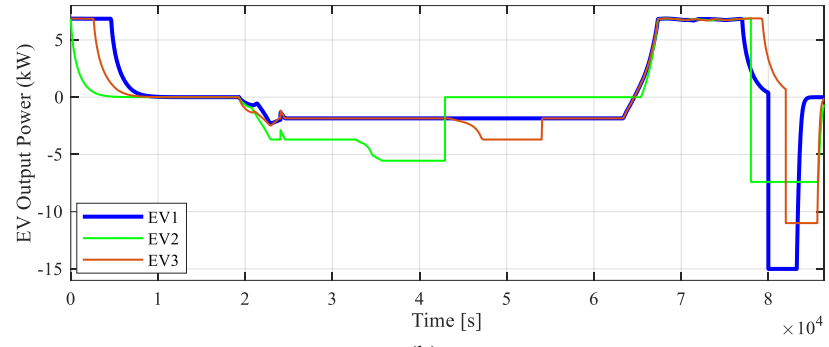

(b)

Fig. 7. The output power of three PEVs for (a) clear day, and (b) cloudy day.

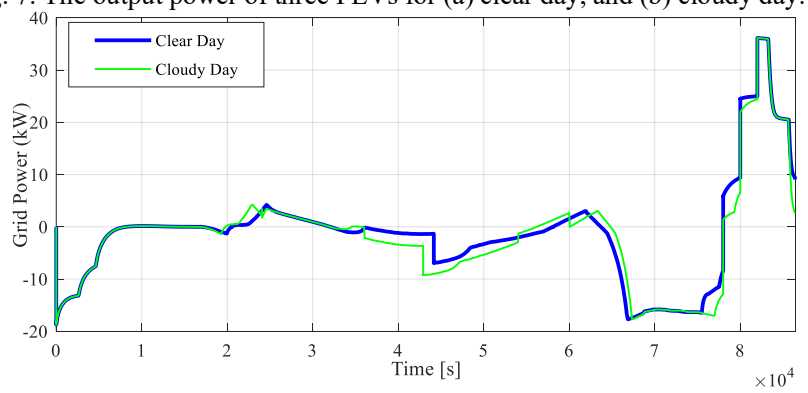

Fig. 8. The grid power for clear and cloudy days.

At the end of the simulation as the departure time of PEVs, all PEVs start charging to reach the finalized SOCs stated in Table III. Fig. 8 illustrates the grid power for both clear and cloudy days. As it can be understood from this figure, when the PV panel power exists, the grid power is attempted to have less power generation and consumption. However, a peak power consuption happens for the grid immediately after full charging state of PEV2, as depicted in Fig. 8. On the other hand, it should be pointed out that the grid power approaches its maximum power consuption when the price is located within its peak period shown in Fig. 2(c).

\section{B. The SOC and Price Analysis}

The proposed smart charging/discharging strategy can provide the SOCs for three PEVs according to Fig. 9 when both clear and cloudy days are applied. As it can be seen from this figure, all SOCs are continously increased with the constant ramp within the interval which $\mathrm{PV}$ panels power reaches its peak values. Among the PEVs, the PEV2 has more charging rate as it has been assessed through Fig. 5. In comparison with the cloudy day, the PEV3 has been charged more in the cloudy day. In addition, all PEVs in the cloudy day have been more discharged while the price is within its peak values compared to the clear day. By noticing both Fig. 9(a) and (b), it can be realized that the proposed smart strategy is able to enable all PEVs to reach their finalized SOC at the departure time.

According to these figures, it is obvious that the PEV1, PEV2 and PEV3 can reach the SOCs of $70 \%, 80 \%$ and $60 \%$, respectively with high accuracy and suitable transient time. As another target of this paper, the results of the price for both clear and cloudy days are illustrated in Fig. 10. This figure displays that high cost benefits can be obtained for both PEVs station and PEVs owners in all day. As it has been scheduled in the proposed smart charging/discharging strategy, when the price is within its peak values, the most cost benefits are driven as dipicted in Fig. 10.

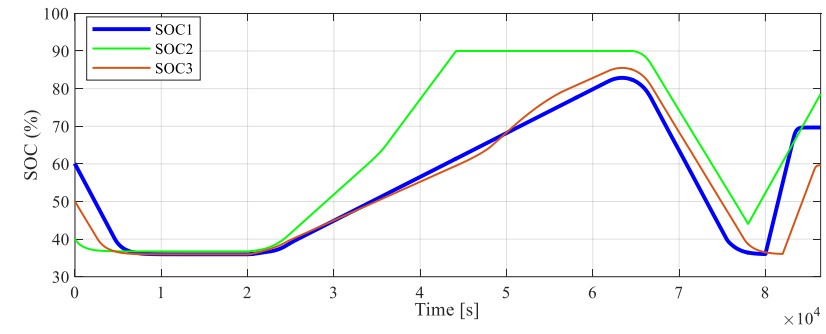

(a)

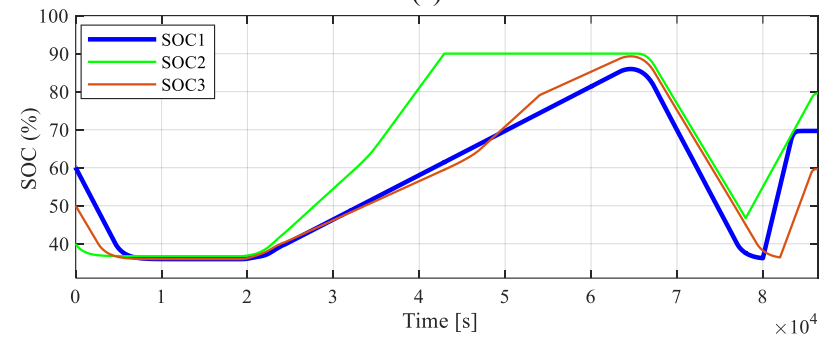

(b)

Fig. 9. The SOC of three PEVs for (a) clear day, and (b) cloudy day.

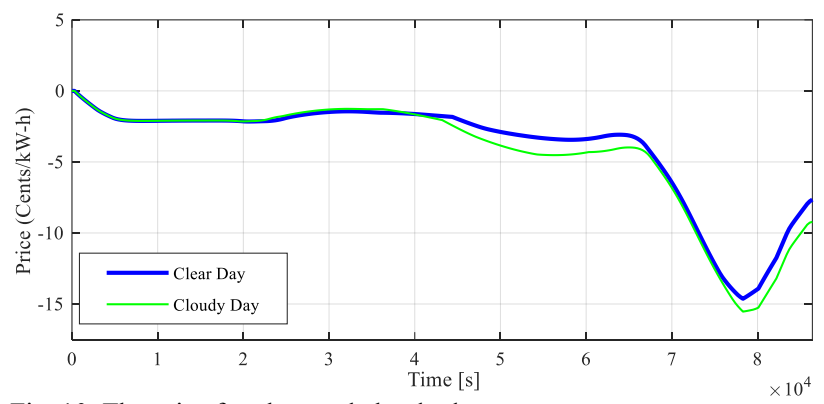

Fig. 10. The price for clear and cloudy days. 


\section{CONCLUSION}

A fuzzy-based smart charging/discharging strategy has been proposed in this paper to manage the output power of PEVs in a smart grid structure. The proposed strategy has consisted of two parts. The first part has been developed using a set of Mamdani FIS rules proportional to the rated output power of PEVs. This part has aimed to reach the utilization of PV panel power as well as bring cost benefits for the PEVs station owner and the PEVs owner. Several 3D and 2D curves have been obtained accordingly to assess the effects of the proposed fuzzy smart strategy on each PEV output power. As another main target of this paper, the second part has been allocated for the setting process of all PEVs SOCs at a specified point when the PEVs have departed from the charging station. To this end, the instantaneous SOC errors have been incorporated by the proposed fuzzy rules for PEVs with varying charging/discharging degrees. Simulation results in MATLAB/Simulink environment have been achieved to verify the validity of the proposed strategy in presence of different PV panel profiles.

\section{REFERENCES}

[1] L. Liu, F. Kong, X. Liu, Y. Peng, and Q. Wang, "A Review on Electric Vehicles Interacting with Renewable Energy in Smart Grid," Renew. Sustain. Energy Rev., vol. 51, pp. 648-661, Nov. 2015.

[2] A. Bindra, "Electric Vehicle Batteries Eye Solid-State Technology: Prototypes Promise Lower Cost, Faster Charging, and Greater Safety," IEEE Power Electronics Magazine, vol. 7, no. 1, pp. 16-19, March 2020.

[3] Khaled Hajar, Baoling Guo, Ahmad Hably, Seddik Bacha, "Smart Charging Impact on Electric Vehicles in Presence of Photovoltaics," ICIT 2021 - 22nd IEEE International Conference on Industrial Technology, Mar 2021, Valencia (virtual), Spain.

[4] H. Turker, S. Bacha, D. Chatroux and A. Hably, "Modelling of System Components for Vehicle-to-Grid (V2G) and Vehicle-to-Home (V2H) Applications with Plug-in Hybrid Electric Vehicles (PHEVs)," 2012 IEEE PES Innovative Smart Grid Technologies (ISGT), 2012, pp. 1-8.

[5] A. Ovalle, A. Hably, S. Bacha, "Grid Optimal Integration of Electric Vehicles: Examples with Matlab Implementation," Springer International Publishing, 2018.

[6] A. Ovalle, A. Hably and S. Bacha, "Escort Evolutionary Game Dynamics Application on a Distribution System with PV, BSS and EVs," 2018 IEEE International Conference on Industrial Technology (ICIT), 2018, pp. 1690-1695.

[7] T. Ding, Z. Zeng, J. Bai, B. Qin, Y. Yang and M. Shahidehpour, "Optimal Electric Vehicle Charging Strategy With Markov Decision Process and Reinforcement Learning Technique," IEEE Transactions on Industry Applications, vol. 56, no. 5, pp. 5811-5823, Sept.-Oct. 2020.

[8] A. Ovalle, A. Hably, S. Bacha and V. Pirsan, "Mixed Strategist Dynamics Application to Electrical Vehicle Distributed Load Scheduling," IECON 2015 - 41st Annual Conference of the IEEE Industrial Electronics Society, 2015, pp. 003169-003174.

[9] A. Florescu, A. I. Bratcu, I. Munteanu, A. Rumeau and S. Bacha, "LQG Optimal Control Applied to On-Board Energy Management System of All-Electric Vehicles," IEEE Transactions on Control Systems Technology, vol. 23, no. 4, pp. 1427-1439, July 2015.
[10] R. Razi, K. Hajar, A. Hably, and S. Bacha, "A User-Friendly Smart Charging Algorithm Based on Energy-Awareness for Different PEV Parking Scenarios," 29th Mediterranean Conference on Control and Automation (MED), Jun. 2021.

[11] S. G. Wirasingha and A. Emadi, "Classification and Review of Control Strategies for Plug-In Hybrid Electric Vehicles," IEEE Transactions on Vehicular Technology, vol. 60, no. 1, pp. 111-122, Jan. 2011.

[12] A. A. Ferreira, J. A. Pomilio, G. Spiazzi and L. de Araujo Silva, "Energy Management Fuzzy Logic Supervisory for Electric Vehicle Power Supplies System," IEEE Transactions on Power Electronics, vol. 23, no. 1, pp. 107-115, Jan. 2008.

[13] F. U. Syed, M. L. Kuang, M. Smith, S. Okubo and H. Ying, "Fuzzy GainScheduling Proportional-Integral Control for Improving Engine Power and Speed Behavior in a Hybrid Electric Vehicle," IEEE Transactions on Vehicular Technology, vol. 58, no. 1, pp. 69-84, Jan. 2009.

[14] K. P. Inala, B. Sah, P. Kumar and S. K. Bose, "Impact of V2G Communication on Grid Node Voltage at Charging Station in a Smart Grid Scenario," IEEE Systems Journal, Early Access, 2021.

[15] M. Ghofrani, A. Arabali, M. Etezadi-Amoli and M. S. Fadali, "Smart Scheduling and Cost-Benefit Analysis of Grid-Enabled Electric Vehicles for Wind Power Integration," IEEE Transactions on Smart Grid, vol. 5, no. 5, pp. 2306-2313, Sept. 2014.

[16] M. Singh, P. Kumar and I. Kar, "A Multi Charging Station for Electric Vehicles and Its Utilization for Load Management and the Grid Support," IEEE Transactions on Smart Grid, vol. 4, no. 2, pp. 1026-1037, June 2013.

[17] J. Teng, S. Liao and C. Wen, "Design of a Fully Decentralized Controlled Electric Vehicle Charger for Mitigating Charging Impact on Power Grids," IEEE Transactions on Industry Applications, vol. 53, no. 2, pp. 1497-1505, March-April 2017.

[18] Reddy K. R, Meikandasivam S, and Vijayakumar D, "A Novel Strategy for Maximization of Plug-In Electric Vehicle's Storage Utilization for Grid Support with Consideration of Customer Flexibility," Electric Power Systems Research, vol. 170, pp. 158-175, May 2019.

[19] S. Hussain, M. A. Ahmed and Y. Kim, "Efficient Power Management Algorithm Based on Fuzzy Logic Inference for Electric Vehicles Parking Lot," IEEE Access, vol. 7, pp. 65467-65485, 2019.

[20] E. Akhavan-Rezai, M. F. Shaaban, E. F. El-Saadany and F. Karray, "Online Intelligent Demand Management of Plug-In Electric Vehicles in Future Smart Parking Lots," IEEE Systems Journal, vol. 10, no. 2, pp. 483-494, June 2016.

[21] D. Phan, A. Bab-Hadiashar, M. Fayyazi, R. Hoseinnezhad, R. N. Jazar and H. Khayyam, "Interval Type-2 Fuzzy Logic Control for Energy Management of Hybrid Electric Autonomous Vehicle," IEEE Transactions on Intelligent Vehicles, Early Access, 2021.

[22] B. Sah, P. Kumar and S. K. Bose, "A Fuzzy Logic and Artificial Neural Network-Based Intelligent Controller for a Vehicle-to-Grid System," IEEE Systems Journal, Early Access, 2021.

[23] Z. Lv, L. Qiao, K. Cai and Q. Wang, "Big Data Analysis Technology for Electric Vehicle Networks in Smart Cities," IEEE Transactions on Intelligent Transportation Systems, vol. 22, no. 3, pp. 1807-1816, March 2021.

[24] H. Turker and S. Bacha, "Optimal Minimization of Plug-In Electric Vehicle Charging Cost With Vehicle-to-Home and Vehicle-to-Grid Concepts," IEEE Transactions on Vehicular Technology, vol. 67, no. 11, pp. 10281-10292, Nov. 2018.

[25] V. Nguyen, T. Tran-Quoc, S. Bacha and B. Nguyen, "Charging Strategies to Minimize the Peak Load for an Electric Vehicle Fleet," IECON 2014 40th Annual Conference of the IEEE Industrial Electronics Society, 2014, pp. 3522-3528. 